\title{
VIVENCIANDO A APRENDIZAGEM COLABORATIVA EM SALA DE AULA: experiências no ensino superior
}

\section{Living collaborative learning in the classroom: experiences on higher education}

\author{
Paulo Roberto Alcântara ${ }^{1}$ \\ Lilia Maria Marques Siqueira ${ }^{2}$ \\ Suzana Valaski ${ }^{3}$
}

\section{Resumo}

Este artigo apresenta os resultados de três pesquisas pedagógicas com alunos dos cursos de Arquitetura e Urbanismo, Engenharia Elétrica e Desenho Industrial na Pontifícia Universidade Católica do Paraná. Os alunos de Arquitetura e Urbanismo tiveram um ensino bimodal. No ensino em sala de aula, foram oferecidas aulas teórico-práticas, assessorias e cenários de atividades de aprendizagem colaborativa baseada em projetos. No ensino virtual, um site na Internet foi construído para apresentar o programa de aprendizagem, o contrato didático e o material didático, e para ajudar os aprendizes na construção de novos conhecimentos. Para ajudar o crescimento da aprendizagem colaborativa em uma abordagem pedagógica de comunidade de aprendizagem em rede, o grupo de alunos usou a interface Eureka. Para os estudantes de Engenharia Elétrica foram propostas três atividades. A primeira foi uma atividade de projeto de aquecimento de ambiente, realizada em sala de aula. A segunda foi uma pesquisa bibliográfica, utilizando a ferramenta fórum do sistema Eureka. A terceira atividade consistiu em

1 Ph.D. em Educação e Desenvolvimento Humano e Mestre em Educação pelo George Peabody College of Vanderbilt University, professor do Programa de Mestrado em Educação da PUCPR, coordenador da Linha de Pesquisa Educação, Comunicação e Tecnologia e professor da Graduação em Pedagogia da PUCPR. Rua Imaculada Conceição, 1155, Prado Velho, Curitiba - PR, CEP 80.215-901.

paulo.alcantara@pucpr.br

2 Mestre em Educação pela PUCPRe professora do Curso de Engenharia Elétrica da PUCPR. Rua Imaculada Conceição, 1155, Prado Velho, Curitiba - PR, CEP 80.215-901.

E-mail: lilia@ppgia.pucpr.br

3 Mestre em Educação pela PUCPRe professora do Departamento de Matemática da PUCPR. Rua Imaculada Conceição, 1155, Prado Velho, Curitiba - PR, CEP 80.215-901.

E-mail: suzana.valaski@pucpr.br 
implementar um circuito elétrico em placa do tipo proto-board para posteriormente confeccionar a placa de circuito impresso. Para os alunos do curso de Desenho Industrial as atividades com projetos desenvolvidas foram estabelecidas a partir da aprendizagem colaborativa, buscando uma forma de utilizar o ensino com pesquisa, que colocou os alunos diante de uma situação de equipe que simulasse uma experiência profissional de criação de páginas da Intemet. Os resultados das pesquisas indicaram que com a aprendizagem colaborativa, novas formas de ensinar e aprender puderam ser desenvolvidas e colocaram os estudantes na interseção de uma gama enorme de interações. Palavras-chave: Aprendizagem colaborativa; Prática pedagógica; Tecnologia educacional

\section{Abstract}

This article presents the results of three pedagogical researches with students of the Architecture and Urbanization, Electrical Engineering and Industrial Drawing courses at the Pontifícia Universidade Católica do Paraná. The Architecture and Urbanization students had a bimodal teaching. In the classroom teaching, theoretical and practical classes, tutorial and scenarios of collaborative learning activities based on projects were offered. In the virtual teaching, a site at the Internet was built to introduce the learning program, the didactic contract and the didactic material, and to help the apprentices on the new knowledge construction. To help the collaborative learning growth in a pedagogical approach of network learning community, the students' group used the Eureka interface. For the Electrical Engineering students three activities were proposed. The first one was an environmental heating project activity, accomplished in the classroom. The second was a bibliographical research using the forum tool of the Eureka system. The third activity consisted of implementing a proto-board plate electrical circuit to make the printed circuit plate. For the Industrial Drawing course students the developed activities with projects were established from the collaborative learning, seeking a form of using the teaching with research, which placed the students in front of a team situation that simulated the professional experience of Internet pages creation. The results of the researches indicated that with the collaborative learning new forms of teaching and learning could be developed and placed the students in the intersection of an enormous range of interactions.

Keywords: Collaborative learning; Pedagogical practice; Educational technology. 


\section{Introdução}

O profissional que exerce a função docente planeja sua atuação em sala de aula, esforçando-se para estar bem preparado e articulado em relação aos assuntos que pretende desenvolver. Dependendo do conteúdo a ser trabalhado, aplica as metodologias que supõe serem as mais adequadas e empreende as avaliações que lhe parecem justas e propícias, porém comumente deixa 0 aluno encarregado de gerenciar sua própria aprendizagem.

Uma alternativa metodológica de modificar a forma de ensinar e de aprender é utilizar a influência entre os pares, chamada de aprendizagem colaborativa. Esta estratégia de ensino-aprendizagem vê o aluno como um sujeito ativo e participante do processo de aprendizagem, onde este interage com os outros colegas e professor, assimilando conceitos e informações e construindo o conhecimento. O significado da palavra conhecimento pode ser visto como uma percepção clara de algo; entendimento; aprendizado; tudo que foi percebido ou apreendido pela mente; experiência prática; habilidade; informação organizada aplicável à solução de problemas. A aprendizagem colaborativa, no entanto, parte da idéia de que existem dois tipos de conhecimento: 0 alicerçado e o não alicerçado. $\mathrm{O}$ alicerçado é o conhecimento elaborado, disponível nos livros. O conhecimento não alicerçado é construído socialmente, pela interação com outros indivíduos. Este conhecimento é possível de ser alcançado quando pessoas estão trabalhando juntas, direta ou indiretamente, conversando e chegando a um acordo (ALCÂNTARA; BEHRENS; CARVALHO, 2001). O professor deve buscar atividades que ajudem os alunos a descobrirem e utilizarem a heterogeneidade do grupo para aumentar o potencial de aprendizagem de cada membro. A aprendizagem colaborativa pode reunir pessoas em grupos de forma presencial ou virtual. Quando empregada de forma virtual, é conhecida como Ambiente Colaborativo ou CSCL (Computer Supported Collaborative Learning), o qual faz uso da Comunicação Mediada por Computador (CMC).

Na aprendizagem colaborativa, os alunos devem reconsiderar seus conceitos, por meio da discussão uns com os outros. Esta interdependência tão necessária na vida profissional é pouco incentivada na visão tradicional do ensino. Na visão de Bruffee (1999): “a educação universitária pode ser vista como essencialmente uma transição de cultura, e este processo só é possível por meio da colaboração". (p.9)

A aprendizagem colaborativa pressupõe um ambiente de aprendizagem aberto em que o aluno se envolve a "fazer coisas e a refletir sobre o que faz", sendo-lhe dada a oportunidade de pensar por si mesmo e de comparar o seu processo de pensamento com o dos outros, estimulando, assim, o pensamento crítico. Para Borges (1995, p. 53), a "aprendizagem colaborativa é uma 
técnica com a qual os estudantes se ajudam no processo de aprendizagem, atuando como parceiros entre si e com o professor, visando adquinir conhecimento sobre um dado objeto".

Apesar de parecer muito restrita, Johnson e Johnson (1997, p. 14) definem aprendizagem colaborativa como sendo: "conjunto de métodos para a aplicação em grupos com o objetivo de desenvolver habilidades de aprendizagem, conhecimento pessoal e relações sociais, onde cada membro do grupo é responsável tanto pela sua aprendizagem como pela do restante do grupo".

Dessa definição se desprendem pelo menos três idéias centrais. A primeira delas se refere a "conjunto de métodos para a aplicação em grupos". Conforme se expressa, estes métodos têm como propósito a modificação, ao menos em parte, do conjunto de relações que se estabelecem entre o professor e seus alunos e entre os próprios alunos. Sua aplicação em grupos deve ser direcionada para o desenvolvimento de atividades em sala de aula e também fora dela. Trata-se de que os alunos trabalhem em grupo não só para que desenvolvam as tarefas propostas, mas para que percebam o próprio processo de aprender. A segunda idéia está relacionada com "desenvolver habilidades de aprendizagem, conhecimento pessoal e relações sociais", pois entrando no desenvolvimento de habilidades e na aquisição de conhecimento, se tem como fundamento a idéia de que tão importante como o que se aprende é também como se aprende. E essa maneira de ensinar e aprender leva os alunos à forma de se relacionar, de viver e de aprender. Os métodos exclusivamente expositivos levam os alunos à passividade e também a um descompromisso em relação a todo o processo. Já na aprendizagem colaborativa busca-se que os alunos além de adquirir conhecimentos, aprendam a relacionar-se com os outros, a expressar e compartilhar idéias, aceitar a diversidade e a desenvolver uma interdependência positiva com seus pares. Por último, a definição fornece uma característica fundamental da aprendizagem colaborativa, que se expressa em "cada membro do grupo é responsável tanto pela sua aprendizagem como pela do restante do grupo". Busca-se que os alunos se comprometam com a sua aprendizagem e aprendam a aprender junto com outros, que seja também sua responsabilidade a aprendizagem dos colegas e onde o êxito do grupo depende de cada um e de todos.

Na essência, a aprendizagem colaborativa, a partir da observação dos grupos de pares, do estudo do processo de comunicação dentro do grupo e entre os grupos, dos fundamentos do ensino com pesquisa, busca técnicas para inovar e melhor alcançar o objetivo maior da educação: a aprendizagem.

Na aprendizagem colaborativa, os professores:

a) Incentivam a autonomia [do aluno] em perceber seu ritmo de estudo e aprendizagem; redirecionam a autoridade da sala de aula 
centrada no professor para os colegas, negociando as relações dentro do grupo, e do grupo para com o professor;

b) Estimulam a interdependência positiva;

c) Auxiliam os alunos a se tornarem autônomos, articulados e mais amadurecidos socialmente;

d) Auxiliam os alunos a aprender a relevância de um assunto não como um conjunto de fatos conclusivos, mas como construído pelo processo da conversação, perguntas e negociação. (BRUFFEE, 1999, p. 89, grifo nosso).

\section{Elementos básicos da aprendizagem colaborativa}

Pedagogicamente, segundo Waggoner, apud Barros (1994), a implementação do aprendizado colaborativo em espaços de ensino está sustentada pelos seguintes pilares:

a) interdependência positiva entre os participantes do grupo;

b) interação face-a-face (vínculo);

c) contribuição individual;

d) desenvolvimento das habilidades interpessoais e de atividades em grupo.

Interdependência Positiva entre os Participantes do Grupo

A interdependência positiva é o elemento central da aprendizagem colaborativa, devido ao fato de que reúne um conjunto de características que facilitam o trabalho em grupo em relação a sua organização e funcionamento (BARROS, 1994). Na interdependência positiva cinco conceitos básicos:

Interdependência de metas: refere-se à existência de objetivos que sejam definidos e compartilhados por todos os elementos do grupo. O professor que quer formar um grupo de aprendizagem colaborativa deverá dar atenção especial para o fato de todos os seus alunos compreendem e compartilham os objetivos definidos para o trabalho. No ensino tradicional habitualmente os alunos desconhecem os objetivos do que está estudando, 0 aluno não compreende a razão do que está sendo ensinado e conseqüentemente aquilo não faz sentido para ele.

Interdependência de tarefas: esta característica consiste na divisão dos trabalhos que desenvolvem os alunos no grupo. Não se deve fazer, como ocorre no ensino tradicional, uma distribuição de trabalhos em que cada aluno faz a sua "parte" de modo passivo, individual e uniforme. A divisão de tarefas na aprendizagem colaborativa deve permitir ao grupo ser mais eficiente no desenvolvimento de suas atividades, no entanto, o aluno deve ter claro 
que sua dedicação pessoal é em beneficio do grupo e dos objetivos desenvolvidos por todos os membros deste. A divisão de tarefas permite que 0 aluno perceba que pode contribuir com o grupo, reforçando, com isso, a auto-estima e a percepção de si como uma pessoa capaz.

Interdependência de recursos: essa característica se refere à divisão dos materiais ou das informações para o desenvolvimento de determinada atividade, por exemplo, se o grupo precisa elaborar um texto sobre determinado tema, cada aluno pode ficar responsável por trazer um artigo ou reportagem sobre o assunto. Isso estimula os alunos a se relacionarem uns com os outros para desenvolver as atividades e chegar aos objetivos combinados. Assim desenvolve-se a capacidade de planejar e coordenar os trabalhos para que a atividade proposta se realize.

Interdependência de funções: consiste em designar diferentes papéis entre os alunos que formam o grupo. Por exemplo, um aluno encarregado de tomar notas numa discussão do grupo, outro responsável pelo material desenvolvido ou pesquisado, outro para manter a comunicação entre os alunos e 0 professor ou entre eles, etc. A interdependência de papéis permite ao grupo 0 controle em relação à ordem das atividades, tempo de execução das tarefas, entre outros. Por outro lado, a designação funções diferenciadas para os alunos permite explorar as habilidades de cada um e isso pode ser útil para que o professor possa ir conhecendo as potencialidades de seus alunos de modo que possa no futuro potencializar essas características ao máximo. Assim, também se resgata a identidade própria de cada aluno, conseguindo aprendizagens que sejam significativas para ele, que podem inclusive ajudar na sua própria forma de ser e de se relacionar.

Interdependência de prêmios: consiste em conceber recompensas conjuntas a todos os integrantes do grupo. É importante que os alunos sintam que o grupo na sua totalidade foi o que levou ao êxito da tarefa e que esse sucesso foi produto do esforço de cada um. Este êxito grupal desenvolve nos alunos sentimentos de pertencer e de apoio coletivo, reforçando-se a idéia de que trabalhar em grupo é produtivo e recompensador.

\section{Interação Facea-Face (Vínculo)}

A interdependência positiva em um grupo de aprendizagem colaborativo não ocorre por acaso. São as formas de interação e de intercâmbio verbal entre as pessoas do grupo, movidas pela interdependência positiva, que afetam os resultados da aprendizagem. A colaboração entre pares ajuda a desenvolver estratégias e habilidades gerais de soluções de problemas pelo processo cognitivo implícito na interação e na comunicação (DÍAZ, 2000). A linguagem é fundamental na estruturação do pensamento, sendo necessária 
para comunicar o conhecimento, as idéias do indivíduo e para entender o pensamento do outro envolvido na discussão e na conversação.

É durante a comunicação que ocorrem as trocas de idéias, discussões e os conflitos entre os pares. Sendo a base das interações sociais, a comunicação é responsável, segundo os socioconstrutivistas, pela catalização do processo de desenvolvimento cognitivo individual. Segundo a corrente sociocultural, é pela comunicação que ocorre o desenvolvimento interpsicológico, a partir do qual conceitos são internalizados e ativamente transformados pelo indivíduo, por meio da reflexão, constituindo, assim, o desenvolvimento intrapsicológico. Já, de acordo com a corrente da cognição situada, a comunicação e todo o contexto social que envolve os seus participantes permite a construção e manutenção de conceitos compartilhados, os quais são considerados produtos do grupo todo.

Agindo de forma conjunta e coordenada, é possível construir uma "Inteligência Coletiva", que é muito mais do que apenas a soma das contribuições individuais, é um todo coletivo construído e reconstruído, elaborado e reelaborado, partilhado e compartilhado, o que certamente é mais enriquecedor para o grupo e também para o indivíduo. É o contato entre os alunos participantes o que lhes permite combinar as metas a serem atingidas, atribuir papéis e estimular ou conter atitudes individuais no desenvolvimento das tarefas.

\section{Contribuição Individual}

Esta característica refere-se à capacidade de dominar e executar parte do trabalho pelo qual o aluno se responsabilizou. Os sujeitos sentem-se parte importante e ativa do processo e passam a assumir uma postura de responsabilidade com relação a sua própria aprendizagem e a do grupo. Assim, surgem as contribuições individuais, dando início ao processo de colaboração, a fim de alcançar os objetivos comuns estabelecidos.

Para que realmente ocorra o trabalho colaborativo, cada membro deve ser capaz de assumir integralmente sua tarefa e participar de todas as atividades para que possa contribuir para o êxito do grupo.

Um dos principais objetivos da aprendizagem colaborativa é a aprendizagem ativa por meio de ações construtivistas. Dessa forma, a aprendizagem colaborativa deve prover meios que possibilitem e estimulem a participação ativa dos alunos na construção de novos conhecimentos por meio da pesquisa, da troca de idéias, da argumentação e da reflexão. Quando os alunos estão engajados em atividades de construção de conhecimentos, eles são motivados pela sensação de posse de suas contribuições e também pela sensação de realização ao ver como suas contribuições refletiram na aprendizagem do grupo. 
Desenvolvimento das Habilidades Interpessoais e de Atividades em Grupo

O desenvolvimento de habilidades de colaboração e trabalho em grupo é um dos pontos mais complexos da metodologia da aprendizagem colaborativa, pois é necessário ensinar aos alunos as habilidades sociais necessárias para colaborar. Também é necessário que os alunos envolvidos nas tarefas do grupo estejam motivados a usar essas habilidades. As habilidades de trabalho grupal, entre outras, são: a capacidade de tomar decisões em grupo, a habilidade de planejar colaborativamente, onde os alunos participantes podem incorporar suas idéias, tanto no processo quanto no produto final. Também é de extrema importância a capacidade com que os membros do grupo determinam a organização, pois são os alunos que devem decidir de que modo vão trabalhar.

De forma geral, as habilidades de trabalho colaborativo são simples e as vemos no cotidiano de nosso trabalho e nas relações com as amizades, já que estas estão presentes em todas as pessoas desde que aprendem a ser seres sociais. As habilidades colaborativas são simples formas de relacionamento com os outros, orientadas para executar uma atividade, podem ser observadas as habilidades de comunicação e interação, a habilidade de saber ouvir, saber falar, compartilhar e sintetizar idéias, opinar e expressar seu próprio pensamento e sentimentos. O grande problema é que com o passar do tempo, as habilidades necessárias para o trabalho colaborativo vão se atrofiando, ou seja, nossos alunos perdem as características para desenvolver trabalhos colaborativos e isso ocorre principalmente porque o sistema educativo atual incentiva atitudes individualistas.

Existe um conjunto de comportamentos que são próprios do relacionamento entre as pessoas, porém, depende de cada aluno a forma com que vai aceitar e conviver com as diversidades, desde as diferenças de opinião até as diferenças étnicas ou de nível social. A capacidade de saber o momento para se expressar, de não pressionar para que se faça apenas 0 que ele deseja, são condutas que afetam tanto o funcionamento como o clima do trabalho no grupo.

É importante que o professor dê a seus alunos tempo e espaços de discussão, para que eles possam analisar o funcionamento de seus grupos e possam perceber como as habilidades pessoais e sociais são sendo desenvolvidas para o êxito e ajuda aos membros do grupo e também que o professor permita a auto-avaliação de seus alunos, de modo que eles possam se dar conta se estão atingindo os objetivos, tanto pessoais quanto de grupo, que haviam sido propostos. 


\section{Pesquisas envolvendo aprendizagem colaborativa}

A seguir apresentamos os resultados de três pesquisas pedagógicas realizadas na Pontifícia Universidade Católica do Paraná que tiveram como base os pressupostos da aprendizagem colaborativa.

\section{Experiência no Curso de Arquitetura e Urbanismo Problema de Pesquisa}

O projeto de investigação visou a buscar metodologias inovadoras que possibilitassem a produção do conhecimento aplicando os pressupostos da aprendizagem colaborativa baseada em projetos, utilizando os diversos recursos disponíveis na sociedade do conhecimento e, em especial, a rede informatizada.

A pesquisa teve como foco o desenvolver processos que focalizassem a aprendizagem. Investigou o seguinte problema: Como construir metodologias que atendam um paradigma inovador e contemplem a tecnologia, em especial, o computador, como ferramenta para auxiliar a aprendizagem colaborativa levando à produção do conhecimento significativo, crítico e transformador?

\section{Metodologia}

A metodologia de pesquisa educacional utilizada na pesquisa foi uma abordagem qualitativa aliada a alguns instrumentos da abordagem quantitativa que viessem a subsidiar o processo. Optou-se por uma pesquisa-ação que demandasse intervenção e inserção no grupo pesquisado com base em Thiollent (1998), ou seja, que exige um envolvimento ativo entre os pesquisadores e a ação dos participantes.

O projeto PACTO (Pesquisa em Aprendizagem Colaborativa com TecnOlogias Interativas) desenvolvido com alunos do programa de aprendizagem Sistemas Estruturais foi dividido em duas etapas, com dois estudos cada. Do total de 366 participantes, as suas distribuições ocorreram da seguinte maneira: (a) na primeira etapa foram envolvidos como participantes no Estudo 1, os 21 alunos dependentes; (b) no Estudo 2, os participantes envolvidos foram duas turmas (manhã e tarde) do sistema regular de ensino com 125 alunos; (c) na segunda etapa do Projeto, realizaram-se outros dois estudos. No Estudo 3, com 120 alunos de duas turmas do sistema regular, com a produção e uso de um kit multimídia em CD-ROM; e (d) no Estudo 4, estiveram envolvidos outros 100 alunos de duas turmas do sistema regular com a revisão e o uso do kit multimídia em CD-ROM.

Descrevem-se aqui depoimentos dos alunos da primeira etapa do projeto. São contribuições colhidas por meio de uma amostragem (i.e., relatos 
de 7 alunos) dos depoimentos de 146 alunos que participaram do projeto sob a orientação de Alcantara, Behrens e Carvalho (2001), nos anos 1999 e 2000, (i.e., divididos em 2000a - turma da manhã e 2000b - turma da tarde) e que permitiram levantar alguns pontos relevantes apontados durante o processo de aprendizagem:

(a) Aprendizagem em grupo - 0 aluno comenta sobre o aprendizado colaborativo de estudos em grupo, situação não vivenciada anteriormente (1999):

(aluno 1) - Uma das qualidades do projeto foi que para mim, para a minha turma aqui a gente fez uma coisa que nunca tínhamos feito, foi se juntar na casa de um colega nosso para estudar, isto a gente nunca tinha feito.

(b) Ensino tradicional versus ensino inovador - o aluno denuncia o descaso do professor tradicional com a aprendizagem individual, sem retirar a responsabilidade do aluno no ensino superior e alertando que 0 aluno só encontra dúvidas nas vésperas das provas. Justifica a importância de uma metodologia que permita um processo contínuo de acompanhamento da aprendizagem aliando as vantagens das aulas presencias e a dos recursos tecnológicos (1999):

(aluno 2) - Numa aula normal, o professor dá aula e se você está aprendendo ou não o problema é seu. O professor olha para os 30, 40, 70 pessoas, ele não olha se você está aprendendo. Não, ele está dando aula, se você está copiando ou se está dormindo em cima do caderno, o problema é seu. Ainda mais em faculdade, que cada uma tem sua responsabilidade. Você só vai ver se você tem dúvidas quando você for fazer a prova ou quando você estiver na véspera da prova, estudando. Aí meu Deus, eu não sei fazer esse exercício, eu vi esse exercício com o professor fazendo, mas eu não sei fazer. Aí marmelada na hora da morte, mata, não é? Eu tenho também umas outras opiniões com relação a Internet. Eu gostei da Internet . Não trocaria a Internet pela aula de antigamente. Por que? Uma, por causa da programação visual e da matéria que a Internet engloba, que eu acho muito mais vasto do que a gente tem em aula, e duas, pela facilidade que a gente tem em se relacionar com o professor. Dúvidas, qualquer sugestão que você tenha, via Internet é fácil. Agora eu também, ao contrário disso, eu não trocaria as matérias de aula inteiras somente pela Internet, por que eu acho que a Internet não vai me ensinar do jeito que eu aprendo com o professor dando aula pra mim. Eu acho que, como eu falei a gente tem que achar um fator comum.

(c) Aperfeiçoamento da metodologia - o aluno defende a proposta metodológica sugerindo um aperfeiçoamento (2000b): 
(aluno 3) - Eu estou achando assim uma experiência, assim, eu acho que é alguma coisa que ninguém gosta de estar passando por esta experiência que tínhamos feito agora, uma aula diferente, tudo diferente, e eu acho que deveria continuar assim, mas que mudasse alguma coisa, que mudasse o que ela falou, que o professor desse uma aula inicial, daí o trabalho individual, daí faz o trabalho coletivo e a prática, e depois na hora de crédito fosse feito, que ele pegasse o nosso trabalho junto com as equipes e corrigisse ali e depois faria uma avaliação, claro daí. Eu acho que o método é ótimo, só deveria ser aperfeiçoado.

(d) Conexão - o aluno relata sobre a conexão do conteúdo teórico com a prática e sobre a percepção de que o segundo semestre tinha total integração com o primeiro (2000b):

(aluno 4) - Eu gostei muito mais deste sistema do que do ano passado, acho que a maioria gostou do ano passado, realmente eu não gostava, porque realmente eu não conseguia, ou seja, todo dia tinha um caso sei lá, mas por exemplo para pegar o caderno para estudar nada, só pegava com uma semana ou duas semanas para começar a ler o que iria ter na prova, da prova eu tentava decorar o máximo possível para entender o que fosse e fazia a prova, agora não o primeiro bimestre tem relação com o segundo, o primeiro bimestre foi fácil, mas o segundo tinha total integração com o primeiro, era uma continuação, muito mais aprofundado com relação ao primeiro e assim é como você começar e a aprofundar tudo isto, acho muito mais interessante, e nos dias quando ele dava aula, principalmente esses dias de aula eu não entendia nada do que ele falava, nada, eu só consegui entender o que ele estava falando outro dia, foi três semanas depois quando eu estava fazendo o trabalho, ahh ali o que ele quis dizer no momento era isto, mas no momento para mim não se viu, obviamente, ai você começa a conectar fios, de como se ligavam as coisas, e coisas que eu aprendi no ano passado, eu comecei a aprender agora no segundo bimestre, porque teve relação, o ano passado eu passei assim bem, mas eu não entendi grande coisa, e agora sim, isto é deter realmente da teoria, você ler, você ler os exemplos, ver as fotos, até o Ronaldo sentado, chutando uma bola, ou sei lá, o Ronaldo sobre uma tábua, tudo isto tinha que ver com o que ia ter no segundo bimestre, muito mais interessante, não teve nenhum momento que você parava de lembrar as coisas, justamente por ter um trabalho duas semanas depois todo, e assim você sempre estava lembrando as mesmas coisas, o ano passado era realmente outro, obviamente dizem que neste tipo de aula você tem que estudar todos os dias, ler seu caderninho, e fazer exercício, coisa que a gente não faz normalmente não é, essa é a verdade, e aqui não você tem que trabalhar sempre. 
(e) Avaliação e postura - os alunos defendem o uso de atividades cumulativas para uma avaliação processual, considerando que a produção individual foi relevante, sendo que a produção coletiva depende do envolvimento e da responsabilidade do grupo. Recomenda pela vivência no processo que a composição de um grupo não deve ser composto por mais de quatro pessoas para ser produtivo (2000b):

(aluno 5) - Quem quer prova aqui?

(aluno 6) - Quem aprova, quem quer prova?

(entrevistador 1) - Quem quer prova?

(entrevistador 2) - Quem aprova o uso de prova?

(aluno 7) - Quem quer fazer como prova?

(aluno 6) - Ahh, quem quer prova?

(vários alunos) - (Risos...)

(aluna 6) - Quem aprova?

(aluno 4) - Ninguém quer prova.

(entrevistador 1) - Então é unânime mesmo esta avaliação.

(aluno 6) - É ficou bem melhor do que o ano passado, não fica acumulado as outras coisas, a entrega de trabalho, você sabe que daqui a duas semanas você vai entregar um trabalho, aquilo vai somar pesquisa, depende de você, não é dos outros, o trabalho individual, eu achei ótimo, o coletivo se você tiver um grupo legal que você estabeleça vamos todos fazer, a partir do momento que um chega assim, ahh, então fica com esta parte e eu fico com esta, não, porque eu quero aprender, o grupo vai mudar de postura, o trabalho prático, eu só achei que foi um grupo muito vasto, muito grande e aí ficou gente que até queria colaborar mas não tinha como, aí por exemplo para fazer uma viga ficam três pessoas para por gesso na viga, e não foi a viga, não deu muito certo, imagine se fossem os dois lá metendo a mão no gesso, eu acho que um grupo de quatro é muito bom.

\subsubsection{Resultados e Conclusões Preliminares}

Os depoimentos acima denotam que houve transformações na aprendizagem dos alunos, onde as condições modificadas e com os arranjos necessários de ensino, oferecidas pelo Projeto PACTO e pela aprendizagem colaborativa com utilização de tecnologias interativas, promoveram as mudanças atitudinais, uma postura com criticidade, o desenvolvimento de aprendizagem em grupo, a comparação crítica do ensino tradicional versus o ensino inovador, a avaliação do trabalho individual versus o trabalho em grupo, a possibilidade de receber ajuda dos pares, a crítica positiva para o aperfeiçoamento da metodologia, o sentido de conexão do conteúdo e a avaliação da postura do aluno.

A partir destes depoimentos, observou-se que existe uma indicação de 
que o papel passivo dos alunos em sala de aula tomou uma nova dimensão com o envolvimento em atividades pedagógicas que promoveram colaboração nos trabalhos individuais e coletivos, apontando que uma das vantagens encontrada na metodologia foi que instigou o contato e o estudo contínuo diante dos assuntos relacionados com a disciplina, associado ao uso de recursos tecnológicos.

Os alunos relataram que se motivaram e aprenderam de maneira diferenciada com a disponibilização de novos recursos didáticos e tecnológicos em função da possibilidade de acesso dos conteúdos, impressão fácil, contato e resposta rápida do professor para sanar dúvidas, fatores que ajudaram na aprendizagem da disciplina.

Na visão dos alunos, a proposta metodológica permitiu uma relação dialógica diferenciada, possibilitando uma aprendizagem mais efetiva em menor tempo comparado ao ensino conservador que tiveram em outras disciplinas.

\section{Experiência no Curso de Engenharia Elétrica}

\section{Problema de Pesquisa}

Como inserir novos procedimentos metodológicos, e quais esses procedimentos, para incrementar o aproveitamento dos alunos do Programa de Aprendizagem de Eletricidade? Seria a aprendizagem colaborativa um dos procedimentos possíveis de se adotar na prática docente para melhorar o desempenho destes alunos?

\section{Metodologia}

Esta pesquisa se desenvolveu em três atividades, com os 44 alunos do primeiro período do curso.

Atividade 1- projeto de um piso aquecido em sala de aula

A atividade teve a duração de três semanas, com duas aulas por semana. Na primeira semana, ocorreu a explicação e orientação para a resolução da tarefa; na segunda semana os grupos debateram e chegaram a um consenso sobre a solução adotada. Na terceira semana houve a apresentação das equipes para os seus colegas, defendendo sua idéia para o aquecimento do ambiente. Entre a primeira e a segunda aula, durante o prazo de uma semana, cada membro da equipe pesquisou material de apoio para subsidiar a discussão do segundo encontro e trouxe suas anotações, folhetos, livros, catálogos para a sala de aula. Com base no material presente na sala, cada elemento do grupo expôs, discutiu, argumentou e sustentou a sua proposta de solução. Finalizado o debate, a equipe compôs um pequeno projeto de entrega ao cliente fictício, tendo o cuidado de fazer constar todas as informações sobre o seu produto, baseandose na metodologia da problematização, conforme Berbel (1999). 
Para concluir e realizar o compartilhamento de idéias, na terceira aula, cada grupo apresentou aos colegas dos outros grupos a solução consensual. Atividade 2 - pesquisa bibliográfica pelo ambiente virtual de aprendizagem - EUREKA

Os mesmos alunos, presentes em laboratório de informática, foram cadastrados no ambiente EUREKA da PUCPR. Receberam também, para sua equipe, a proposição de um tema específico do Programa de Aprendizagem, ainda não abordado nas aulas expositivas. Diferentemente das pesquisas tradicionais, os alunos de cada equipe pesquisaram dados para outras duas equipes e apenas recebiam contribuições de seus pares sobre o seu assunto de pesquisa. A intenção desse procedimento foi incentivar o desenvolvimento da responsabilidade entre os colegas, e da interdependência, pois o aluno estava responsável pela coleta de material para o seu colega, e não para si próprio.

No fórum de discussões do ambiente EUREKA foram inseridos 12 diferentes tópicos, de interesse do Programa de Aprendizagem como conteúdo complementar, e a autora optou por restringir a discussão dentro de um conjunto de três ou quatro equipes para que obtivesse um grupo de 15 ou 16 alunos trabalhando em conjunto. Sendo o tempo para elaboração da tarefa de duas semanas, para não prejudicar a qualidade da triagem e seleção dos materiais consultados, a autora optou pela seguinte estratégia: cada grupo pesquisou os assuntos referentes aos das outras duas equipes e recebeu dessas mesmas equipes contribuições para o seu assunto de interesse. De posse desse material para consulta, o grupo analisou os melhores materiais e elaborou um resumo sobre 0 assunto, contendo os aspectos principais citados no roteiro previamente fornecido. Basicamente, a atividade 2 consistia de dois momentos principais, um individual, para o aluno realizar a pesquisa do material e fornecer às equipes do seu conjunto, e o outro em grupo, para cada elemento ajudar a selecionar a qualidade dos documentos recebidos e eleger aquele que serviria de base para a elaboração do resumo.

Atividade 3 - produção de placa de circuito impresso realizado em laboratório de experimentos

Em aula de laboratório, os alunos tiveram a oportunidade de se dividirem em três duplas e seis trios e decidirem pela implementação prática de um circuito elétrico. Entretanto, a escolha de circuito deteve-se a aplicações usando componentes e conceitos que serão aprofundados nos Programas de Aprendizagem de Circuitos Elétricos I e Eletrônica I, buscando o perfeito encadeamento dos Programas de Aprendizagem do Curso.

Na primeira aula, foi realizada a montagem em placa do tipo protoboard, que não utiliza solda, e simula as ligações entre os componentes do circuito. Houve uma avaliação dessa etapa. No segundo encontro, os alunos, de posse dos materiais necessários, procederam ao projeto da fiação impressa e 
transcrição dessa para a placa. Para concluir, houve a oportunidade para a montagem e teste do circuito definitivo e a elaboração de um relatório técnicocientífico contendo as informações sobre o funcionamento do circuito.

\section{Resultados e Conclusões Preliminares}

Ao término de cada uma das atividades propostas, os alunos foram solicitados a preencherem um questionário de avaliação, com perguntas abertas e fechadas. As respostas às perguntas abertas levantadas pelos questionários de avaliação da primeira atividade proposta mostraram que mesmo havendo uma certa semelhança com trabalhos em grupo já realizados em sua vida escolar, os alunos consideraram que a atividade fortaleceu o sentimento de equipe. As diversas soluções apresentadas pelos grupos enriqueceram o desenvolvimento dos trabalhos, não havendo projetos exatamente iguais. Os encontros presenciais e a busca de materiais favoreceram a adaptação entre os participantes. Cada componente da equipe contribuía com o seu conhecimento, que passava pela aprovação, correção ou até mesmo rejeição dos colegas. Os alunos estavam atraídos pela idéia de criar uma solução, de apresentar uma altemativa para 0 cliente.

Na segunda atividade, avaliamos a colaboração mediada por tecnologia, que exigiu as habilidades de facilidade de operação do ambiente EUREKA e pesquisa bibliográfica por meio da Intemet. Entre quatro a cinco alunos, entretanto, ausentaram-se da PUCPR e não utilizaram a reserva de laboratónio disponibilizada pela professora.

A atividade 3 aliou colaboração ao interesse dos alunos que apenas ingressavam no curso de Engenharia: a montagem de circuitos. Pelas respostas aos questionários, percebeu-se uma grande interação entre as equipes. Durante o desenvolvimento da atividade houve uma troca de habilidades, por ser essa uma atividade quase artesanal que exige manuseio dos equipamentos e do instrumental, desfavorecendo a competição, incentivando a colaboração, um ambiente de "ou nos ajudamos ou afundamos juntos". Os resultados desta pesquisa apontaram que a aprendizagem colaborativa: propiciou o aumento de interesse no tema de estudo; resultou em uma melhor interação entre os alunos, fortalecendo a união dentro das equipes; auxiliou no desenvolvimento e amadurecimento das habilidades sociais; ampliou a visão do aluno quanto à aplicabilidade dos conceitos estudados em sala de aula; estimulou o desenvolvimento e o amadurecimento das habilidades técnicas; possibilitou o amadurecimento da habilidade de auto-avaliação; desenvolveu a consciência de equipe; auxiliou a visualizar a contribuição do Programa de Aprendizagem Eletricidade na formação do engenheiro eletricista. 


\section{Experiência no Curso de Desenho Industrial}

\section{Problema da Pesquisa}

Como desenvolver uma prática pedagógica baseada em aprendizagem colaborativa que utiliza os recursos da tecnologia, em especial o uso do computador, com a perspectiva de criar ambientes em que os recursos da informática atuem como facilitadores do processo de ensino-aprendizagem?

\section{Metodologia}

A implementação da aprendizagem colaborativa no Curso de Desenho Industrial teve como principal objetivo propor um modelo de prática pedagógica baseada na aprendizagem colaborativa usando a Internet como principal fonte de pesquisa e divulgação dos trabalhos realizados pelos alunos.

A metodologia de pesquisa foi uma pesquisa-ação, que está associada a diversas formas de ação coletiva e que foi orientada em função da resolução de problemas ou de objetivos de transformação. Foram utilizados dois elementos para a coleta de dados: a análise do material produzido pelos alunos e entrevistas semi-estruturadas. Os dados revelaram as potencialidades do modelo, evidenciando suas vantagens e dificuldades.

No curso de Desenho Industrial, o Programa de Aprendizagem de Matemática I tem como ementa os fundamentos da geometria plana e espacial, aplicados na prática do desenho industrial. Com o propósito de ajudar 0 aluno a construir um senso de colaboração profissional, fundamental à atividade do designer, procurou-se desenvolver uma metodologia em que o aluno valorizasse o processo de aprendizado e se posicionasse com seriedade frente aos estudos e novos desafios, buscando associar os temas propostos com sua futura atividade profissional, percebendo a importância da geometria na relação de construção de um adequado embasamento teórico-conceitual e prático vinculado às necessidades do mercado produtivo, aliando criatividade e competência na elaboração de projetos voltados para a pesquisa e criação de páginas da Internet, uma das áreas de atuação do profissional de Programação Visual.

Behrens (2000) apresenta algumas fases ou passos do projeto de aprendizagem colaborativa e destaca que essas fases não são estanques nem precisam ser ordenadas como se apresentam, cabendo ao professor analisar e propor seu próprio projeto. As fases propostas foram utilizadas como forma de estruturação do trabalho desenvolvido:

Fase 1 - Apresentação e Discussão do Projeto, Problematização e Contextualização.

Esta fase constituiu o momento de explicitar e ajustar o modelo pedagógico, ouvir as resistências dos alunos e levá-las em consideração. Foi um 
passo decisivo para favorecer um ambiente socioafetivo e intelectual promissor para o encaminhamento do processo. Foi o momento de relacionar os objetivos e metas a serem atingidas.

Nesta etapa, os alunos souberam que trabalhariam em grupos e que cada grupo teria como objetivo desenvolver uma página na Internet com um dos temas de estudo do programa de aprendizagem. Eles ficaram cientes de que a pesquisa do conteúdo para a elaboração da página seria feita de duas formas: uma individual e outra coletiva. Também foi discutida a avaliação tendo em vista que ela seria processual e que não estaria vinculada apenas ao trabalho final, mais sim envolveria a avaliação feita pelo professor, por um profissional de web-design, pelos colegas e a própria auto-avaliação.

Fase 2 - Pesquisa e Produção Individual.

Após a formação das equipes, houve uma distribuição interna relativa aos temas da pesquisa individual na Internet. Cada aluno pesquisou sobre um dos temas propostos, excetuando o tema do próprio grupo. Os alunos entregaram sua pesquisa para o grupo responsável pelo tema. Ao final da primeira fase, cada grupo teve um número de contribuições no máximo igual ao total de grupos da sala.

Fase 3 - Discussão Crítica, Produção Coletiva e Produto Final.

Uma vez recebida a contribuição dos alunos, os grupos ficaram responsáveis por realizar uma pesquisa bibliográfica sobre o seu tema, para ter um parâmetro de comparação com os materiais recebidos e poder avaliar 0 conteúdo das pesquisas individuas, inclusive de erros conceituais. A equipe também ficou responsável por avaliar a pertinência ou não do trabalho individual em função da sua aplicabilidade na criação da página. Após o processo individual, a meta foi que os alunos iniciassem o trabalho conjunto, trocassem informações, compartilhassem, explicassem, ouvissem, criando espaços de interação e colaboração e que buscassem a construção coletiva do conhecimento, informada pelos diferentes olhares e pelas negociações, objetivando a construção da página.

Fase 4 - Avaliação.

A avaliação foi sendo realizada durante todas as fases e a nota final de cada aluno constitui-se basicamente em pesquisa individual, página da Web, exercícios entregues resolvidos pelo grupo, participação e resolução das atividades propostas nas aulas expositivas, avaliação feita pelos colegas de grupo, auto-avaliação e uma prova individual no final do processo.

\section{Resultados e Conclusões Preliminares}

Por meio da entrevista semi-estruturada e dos dados obtidos, foi possível perceber que para levar o educando a interagir, comunicar-se com o professor e colegas, é necessário que se sinta motivado pelo objeto de estudo. A maior 
parte dos alunos sabe que a capacidade de trabalhar em grupo é uma das características mais valorizadas atualmente pelas empresas, e que é muito importante para sua vida profissional saber trabalhar em grupo. Segundo os próprios alunos, foi uma ótima oportunidade para aprender a trabalhar com outras pessoas e até para fazer novas amizades. Pesquisar na Internet e verificar se o conteúdo obtido tinha o rigor de conceitos obtidos numa pesquisa bibliográfica teve um resultado bastante interessante. Num primeiro momento, observou-se em muitos trabalhos apenas uma aproximação superficial das informações. Por este motivo, foi necessário que muitos alunos repetissem as pesquisas individuais. Utilizar os trabalhos individuais para desenvolver o trabalho do grupo acabou sendo uma das etapas mais produtivas do processo. Segundo os próprios alunos, ao juntar e guardar as informações úteis, selecionar, analisar e filtrar as de maior valor e ao organizar as informações de forma lógica, foi o momento em que realmente ocorreu a aprendizagem. Ficou claro que o processo tomou-se motivante porque estava pautado na reflexão e depuração de idéias e das informações recebidas de outros alunos.

Construir a página da Web auxiliou e estimulou os alunos a refletirem sobre as informações obtidas a fim de transformá-las em conhecimento. Percebeu-se que é fundamental dar ao aluno a oportunidade de analisar, relacionar e comparar as informações enquanto depura o objeto que está construindo, num processo contínuo que favorece a construção de conhecimento e o conduz à finalização do objeto que se propôs a criar. Em relação à avaliação, foi possível verificar que praticá-la em ambiente colaborativo de aprendizagem requer uma certa capacidade de se desaprender de uma cultura avaliativa centrada única e exclusivamente no professor. Os alunos acharam interessante apesar de não estarem habituados a serem avaliados dessa forma. O resultado da avaliação foi bem aceito pelos alunos. Outro ponto importante foi que as aulas expositivas contribuíram para que os alunos se sentissem seguros do processo e apoiados pelo professor. Os alunos que realmente se envolveram com todo o processo acabaram tendo muitos benefícios por meio da aprendizagem com os colegas. No caso dos alunos sem experiência, eles ficaram mais limitados no início e dependeram mais do professor e dos colegas. Esse processo foi positivo, pois motivou muitos alunos a aprender e outros a ensinar o que já conheciam.

\section{Considerações finais}

A aprendizagem colaborativa como uma metodologia construtivista apresenta características e elementos para que o professor possa criar um ambiente que favoreça a colaboração entre os participantes, a inovação, a pesquisa, a troca de informações e a negociação de conflitos, oferecendo recursos para a aprendizagem individual e coletiva. De forma geral deve-se desenvolver práti- 
cas pedagógicas que criem condições para que os alunos aprendam a construir soluções, principalmente diante de novos problemas. É fundamental na aprendizagem colaborativa envolver a pesquisa não somente como busca de conhecimento ou simples descoberta, que termina na analise teórica, mas como forma natural de estabelecer o diálogo com a realidade. Ou seja, encontrar meios que auxiliem e estimulem os alunos a refletirem sobre as informações obtidas, a fim de que eles possam transformá-las em conhecimento, ou seja, em informação processada e agregada às estruturas mentais já existentes.

Durante as pesquisas, um dos pontos relevantes foi a possibilidade de se estar atento à complexidade do fazer docente. A produção escrita da investigação, a necessidade de revisá-la e poli-la propiciou distanciamento em relação à ação, levando à capacidade de abordar e examinar o próprio trabalho. Pela pesquisa foi possível perceber que na aprendizagem colaborativa a aprendizagem é algo que decorre diretamente da ação do aluno. A participação do professor no processo é indireta. O professor deixa de ser o detentor único e exclusivo de informações e conhecimentos e passa a ser, principalmente, o motivador, o incentivador, o animador, o instigador, o facilitador do aprendizado do aluno (tanto no aspecto cognitivo como nos aspectos afetivoemocional e interpessoal). Porém é fundamental o papel do professor no trabalho, pois cabe a ele as indagações, questionamentos e acompanhamento dos trabalhos dos grupos, para que a proposta de trabalho não se perca logo no início, perdendo o sentido da aprendizagem colaborativa. Assim, no ambiente colaborativo, o professor passa a ser o orientador e desafiador e se torna essencial motivar o grupo e monitorar a participação dos alunos, levando em conta os objetivos e interesses do grupo.

A aprendizagem colaborativa se diferencia consideravelmente da teoria e da prática da aprendizagem tradicional e requer uma aproximação diferente com os alunos. Para que se consiga a máxima efetividade no processo de aprendizagem, são necessários o engajamento e a participação ativa tanto do professor quanto do aluno. A criação de um ambiente de confiança, respeito às diferenças e reciprocidade, encoraja o aluno a reconhecer os seus conflitos e a descobrir a potencialidade de aprender a partir deles mesmos.

\section{Referências}

AlCANTARA, P. R., BeHRenS, M. A., CARVAlHO, R. G. Projeto Pacto: pesquisa em aprendizagem colaborativa com tecnologias interativas (19992000). Curitiba, PR: Pontifícia Universidade Católica do Paraná, 2001. CD - ROM

BARROS, L A. Sistemas de suporte a ambientes distribuídos para aprendizagem cooperativa, 1994. Tese (Doutorado) - COPPE/UFRJ, Rio de janeiro, 1994. 
BEHRENS, M.; MORAN, J. M.; MASETTO, M. Novas tecnologias e mediação pedagógica. Campinas: Papirus, 2000.

BERBEL, N. Metodologia da problematização: fundamentos e aplicações. Londrina: Ed. UEL,1999.

BORGES, M.; CAMPOS, M. L.; CAVALCANTI, M. C. R. Suporte por computador ao trabalho cooperativo. In: CONGRESSO BRASILEIRO DA SOCIEDADE BRASILEIRA DE COMPUTAÇÃO, 15., e JORNADA DE ATUALIZAÇÃO EM INFORMÁTICA, 14., Canela, 1995. Anais... Canela: [s. n.], 1995. p. 51-68.

JOHNSON, D.; JOHNSON R. Learning together and alone: cooperative, competitive, and individualistic learning. Boston, MA: Allyn \& Bacon, 1997.

KUMAR, V. Computer-Supported Collaborative Learning: issues forresearch. Department of Computer Science, University of Saskatchewan, Canada. 1996. Disponível em: http://www.cs.usask.ca/grads/vsk719/academic/890/project2/ project2.html Acesso em 22 nov. 2003.

MORAN, J. M. Mudar a forma de ensinar e de aprender com tecnologias. Disponível em: http://www.eca.usp.br/prof/moran/uber.htm Acesso em 15 out. 2003.

OTSUKA, J.; TAROUCO, L. Proposta de um sistema de apoio à aprendizagem colaborativa baseado na WWW. In: SIMPÓ SIO BRASILEIRO DE INFORMÁTICA EMEDUCAÇÃO , 8., São José dos Campos, 1997. Anais... São José dos Campos: [s. n.], 1997.

TIJIBOY, A. V.; MAÇADA, D.; SANTAROSA, L M.; FAGUNDES, L Aprendizagem Cooperativa em Ambientes Telemáticos. Informática na Educação: teoria \& prática. PGIE/UFRGS, 1999.

SIQUEIRA, Lilia M.M. A metodologia de aprendizagem colaborativa no programa de aprendizagem no curso de Engenharia Elétrica. Curitiba. Dissertação (Mestrado) - Pontifícia Universidade Católica do Paraná, Curitiba, 2003

VALASKI, Suzana. AAprendizagem colaborativa com o uso de computadores: uma Proposta para a Prática Pedagógica. Curitiba. Dissertação (Mestrado) - Pontifícia Universidade Católica do Paraná, Curitiba, 2003. 